\title{
Acute Diverticulitis: A Rare Cause of Abdominal Pain
}

\author{
Muhammad Umar Kamal ${ }^{\mathrm{a}}$, Ahmed Baiomi ${ }^{\mathrm{a}, \mathrm{b}}$, c , Bhavna Balar ${ }^{\mathrm{a}}$, b
}

\begin{abstract}
There is an increasing incidence of diverticulosis and diverticulitis in the younger populations; and its occurrence in very young individual is concerning. Here we report a rare and interesting case of a 20 -yearold man who presented with 3-day history of epigastric abdominal pain associated with diarrhea and nausea. His abdominal examination revealed mild tenderness in the right lower abdominal quadrant. Computed tomography (CT) scan of abdomen with intravenous contrast revealed scattered diverticula throughout the colon with focal thickening, pericolonic infiltrative changes suggestive of acute diverticulitis in the distal ascending colon. He was treated with intravenous hydration and antibiotics and discharged when his clinical status improved. He underwent colonoscopy 1 month later which showed pan diverticulosis. This case illustrates the importance of considering acute diverticulitis in the differential diagnosis of right lower quadrant pain when evaluating a young patient.
\end{abstract}

Keywords: Acute diverticulitis; Young individuals; Diverticulosis; Diverticular disease; Gastrointestinal disease; Epidemiology; Age factors; Severity

\section{Introduction}

Diverticular disease is commonly seen in older individuals in the western countries and usually involves left side of the colon. The pathogenesis of diverticular disease is thought to be multifactorial and include both environmental and genetic factors in addition to the historically accepted etiology of dietary fiber deficiency, disordered motility or structural changes of the colon $[1,2]$. The disease prevalence increases with age and approximately $65 \%$ of the western population has diverticulosis by age of 85 [3-5]. Previous studies have reported that less than $10 \%$ of populations younger than 40 years of age have

Manuscript submitted March 11, 2019, accepted May 5, 2019

aDepartment of Medicine, BronxCare Hospital Center, Bronx, NY 10457, USA

bivision of Gastroenterology, Department of Medicine, BronxCare Hospital Center, Bronx, NY 10457, USA

${ }^{\mathrm{c} C}$ Corresponding Author: Ahmed Baiomi, Department of Medicine, Bronx Lebanon Hospital Center, 1650 Selwyn Ave, Suite 10C, Bronx, NY 10457, USA. Email: Abaiomi@bronxleb.org

doi: https://doi.org/10.14740/gr1166 diverticulosis [6]. More recent studies have reported increasing incidence of diverticulosis and diverticulitis in the younger populations [7, 8]. Life style changes and obesity in addition to low dietary fiber predispose the young population towards colonic diverticulosis [9-13]. Role of vitamin D deficiency in pathogenesis of acute diverticulitis remains conjuncture [14].

Majority of the younger population with diverticulosis never develops symptoms, but around $10-25 \%$ suffers from episodes of diverticulitis $[15,16]$. Diverticulitis has a wide range of clinical severity ranging from mild abdominal pain to the development of acute abdomen due to perforation and peritonitis [17]. Clinical course and outcomes of diverticulitis in the younger populations have evolved overtime in the reported studies. Initial studies have described a severe clinical presentation with more complications [1, 2, 10, 18-21]. However, some recent studies have reported milder clinical outcomes which are not different from the older population [7, 17, 22].

There are no definitive guidelines regarding the management of acute diverticulitis in the young population [7, 23-25]. Most practices follow the same guidelines as for older population. Here we report a rare case of acute right-sided diverticulitis in a 20 -year-old man.

\section{Case Report}

A 20-year-old Middle Eastern man presented to the emergency department with 3-day history of abdominal pain in the epigastric area, radiating to the right lower quadrant, associated with diarrhea and nausea. Diarrhea was watery brown stool without blood or mucus. He denies any history of fever. Patient smoked few cigarettes per day. On initial examination in the emergency department, patient was afebrile, in mild distress due to pain with stable vital signs. His abdominal examination revealed mild tenderness in the right lower abdominal quadrant without any peritoneal signs. Rest of the review of systems and physical examination was unremarkable. Laboratory tests are discussed in Table 1. Stool examination was negative for Clostridium difficile and occult blood testing.

Ultrasound of the abdomen showed non-visualization of the appendix. Computed tomography (CT) scan of abdomen with intravenous contrast revealed scattered diverticula throughout the colon with focal thickening, pericolonic infiltrative changes suggestive of acute diverticulitis in the distal ascending colon and normal appendix. This is elaborated in Figure 1.

Patient was admitted to pediatric floor and started intravenous hydration and antibiotics. He received intravenous cefoxitin $1 \mathrm{~g}$ every $6 \mathrm{~h}$ and oral metronidazole $500 \mathrm{mg}$ every 8 
Table 1. Initial Relevant Laboratory Values on Presentation

\begin{tabular}{lll}
\hline Laboratory test & Result (normal range), day $\mathbf{1}$ & Result (normal range), day 2 \\
\hline Hemoglobin & $14.8 \mathrm{~g} / \mathrm{dL}(12-16 \mathrm{~g} / \mathrm{dL})$ & $13.5 \mathrm{~g} / \mathrm{dL}(12-16 \mathrm{~g} / \mathrm{dL})$ \\
Hematocrit & $42.5 \%(42-51 \%)$ & $39.2 \%(42-51 \%)$ \\
Leukocyte count & $7,100 / \mu \mathrm{L}(4,800-10,800 / \mu \mathrm{L})$ & $6,100 / \mu \mathrm{L}(4,800-10,800 / \mu \mathrm{L})$ \\
Platelet count & $259,000 / \mu \mathrm{L}(150,000-400,000 / \mu \mathrm{L})$ & $228,000 / \mu \mathrm{L}(150,000-400,000 / \mu \mathrm{L})$ \\
Blood urea nitrogen & $13 \mathrm{mg} / \mathrm{dL}(8-26 \mathrm{mg} / \mathrm{dL})$ & $9 \mathrm{mg} / \mathrm{dL}(8-26 \mathrm{mg} / \mathrm{dL})$ \\
Serum creatinine & $0.8 \mathrm{mg} / \mathrm{dL}(0.5-1.5 \mathrm{mg} / \mathrm{dL})$ & $0.7 \mathrm{mg} / \mathrm{dL}(0.5-1.5 \mathrm{mg} / \mathrm{dL})$ \\
Serum albumin & & $3.9 \mathrm{~g} / \mathrm{dL}(3.2-4.6 \mathrm{~g} / \mathrm{dL})$ \\
Serum total bilirubin & & $1.0 \mathrm{mg} / \mathrm{dL}(0.2-1.1 \mathrm{mg} / \mathrm{dL})$ \\
Alkaline phosphatase & & $207 \mathrm{U} / \mathrm{L}(43-160 \mathrm{U} / \mathrm{L})$ \\
Serum alanine aminotransferase & & $15 \mathrm{U} / \mathrm{L}(5-40 \mathrm{U} / \mathrm{L})$ \\
Serum aspartate transaminase & & $12 \mathrm{U} / \mathrm{L}(9-36 \mathrm{U} / \mathrm{L})$ \\
C-reactive protein & $72 \mathrm{mg} / \mathrm{dL}(<5 \mathrm{mg} / \mathrm{dL})$ & \\
\hline
\end{tabular}

h. He was kept without any oral intake till his nausea and pain improved. When he was able to tolerate oral diet, he was discharged on oral antibiotics.

A month later he was seen in the gastroenterology clinic, where he reported that he was symptom free. He underwent colonoscopy which showed pan diverticulosis. Patient was advised to follow high fiber diet and quit smoking.

\section{Discussion}

In the last two decades, the incidence of diverticulitis in the population younger than 40 years of age have been increasingly reported but it is extremely rare in very young individuals such as our patient $[1,26]$. To our knowledge this is the first case of acute diverticulitis in a young adult man. Previously similar age case was reported in a woman of the same age.

There is an increasing incidence of diverticular disease in the younger population and its occurrence in very young individual is concerning. Etzioni et al reported that more patients are diagnosed and treated for diverticulitis in recent years as compared to past [26]. This may be due to the more frequent use of CT scan aiding in the diagnoses, in addition to the clinical presentation. Comparing the disease statistics of 2005 with 1998 , there was notable $26 \%$ increase in rates of hospitalization for acute disease, and a $38 \%$ increase in the rates of elective surgeries for diverticulitis in general population. In the younger population (age 18 to 44 years), there was even more profoundly increased rates of hospital admission (by $82 \%$ ) and elective surgeries (by 73\%) [26].

Right-sided diverticulosis is commonly seen in Asian countries and is largely associated with genetic predispositions [1]. It has been speculated that hypoganglionosis or aganglionosis are causative etiology for the pathogenesis of right-sided diverticulitis [27]. Increasing incidence of diverticular disease in other parts of world could be due their adoption of Western

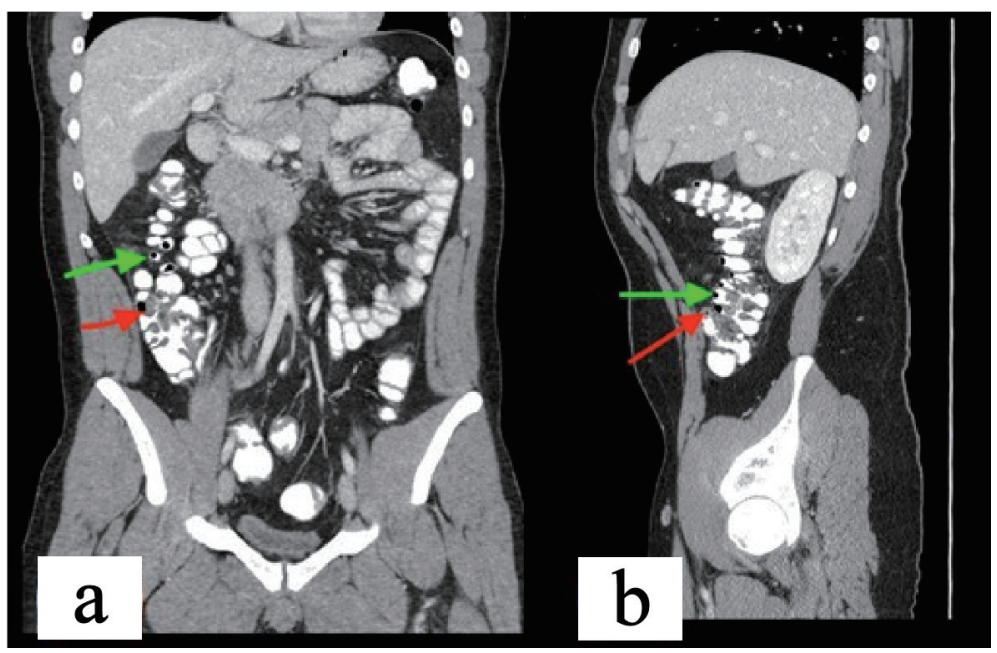

Figure 1. CT of the abdomen and pelvis with coronal (a) and sagittal (b) sections, green arrow pointing to the diverticulae and the red arrow pointing to thickened bowel wall. 
life style and diet.

Diverticulosis is thought to occur due to multiple factors including low fiber intake, disordered colonic motility, structural abnormalities in the colon and genetic factors $[1,28,29]$. Many recent trials have reported obesity as a risk factor leading to higher incidence of diverticulitis and its related complications especially in younger men $[10,11,13,30]$. Obesity was also reported to be significantly associated with diverticular complication such as bleeding, perforation, and recurrent diverticulitis in young male population [10, 31, 32]. Pisanu et al also demonstrated significant association of acute diverticulitis in young male patients with a BMI $\geq 25$ and chronic consumption of alcohol in terms of moderate and occasionally excessive doses [9]. Nonsteroidal anti-inflammatory drugs (NSAIDs) and aspirin use also has been reported to be associated with diverticulitis [33].

Abdominal CT scan with oral and intravenous contrast is the test of choice to diagnose acute diverticulitis with high sensitivity (93-96\%) and specificity (100\%) [34]. It also helps in assessing the severity of inflammation, and therefore categorizes the diverticulitis into complicated or uncomplicated disease [34, 35], as well as excluding other pathology as a cause of abdominal pain. Fever $\left(\geq 38^{\circ} \mathrm{C}\right)$ on admission predicts increased risk of complications from acute diverticulitis in patients under 40 years of age [32].

Due to rarity of the disease, the clinical outcomes and severity of acute diverticulitis in younger patients have not been clearly defined yet. Previously acute diverticulitis in younger patients was considered an aggressive diseases and surgical treatment was recommended to prevent recurrent attacks $[2$, 5]. Subsequently other studies recommended management in younger patients less than 40 years of age to be similar to the older age group. Some studies mentioned that recurrent attacks of acute diverticulitis and management occur with similar frequency in all age groups and respond equally to medical treatments $[33,36]$. The risk of severe disease and complications is comparable among older and younger patients $[7,8]$. However, other studies have found severe disease and increased recurrent episodes of diverticulitis in young patients as compared to older patients and also younger patients requiring more surgical interventions comparatively [3, 26, 33]. Few cases of acute diverticulitis are only diagnosed when operated for suspected appendicitis [37].

We reviewed our own institution admission data for acute diverticulitis over past 10 years. Among 1,800 patients with acute diverticulitis diagnosis, there were only two adolescents [38] (18 and 19 years of age). The youngest adult patient was our case reported here. Review of literature has revealed approximately eight cases in adolescents [19, 21, 39-42] and three in pediatric population [39].

Acute diverticulitis is not routinely considered in differential diagnosis when evaluating pediatric, adolescent or very young adult patients. With rising incidence of this disease, it is important that clinician consider this as a possible diagnosis when evaluating a patient with symptoms of lower abdominal pain. Appendicitis and the ovarian torsion should be in the differential diagnosis of acute diverticulitis or appendicitis in the appropriate clinical settings $[1,37]$.

The management of acute diverticulitis in the young can be similar to the older patients $[16,43]$. Recent literature suggests that indication for surgery for acute diverticulitis should not be only based on age or number of episodes of diverticulitis [36]. Antibiotics are the mainstay of treatment for uncomplicated diverticulitis. The latest guidelines suggest selective, rather than routine use of antibiotics in patients with acute diverticulitis [36].

\section{Conclusions}

Acute right-sided diverticulitis is extremely rare in young adult population. The clinical presentation is often misleading as symptoms are similar to acute appendicitis which is much more common in this age group. Severity of acute diverticulitis guides the management strategies. There are no consensus guidelines regarding number of recurrent attacks and need for elective surgical management. Our case illustrates the importance of considering acute diverticulitis in the differential diagnosis of right lower quadrant pain when evaluating a young patient.

\section{Acknowledgments}

None to declare.

\section{Financial Disclosure}

None of the authors have any financial conflicts of interest.

\section{Conflict of Interest}

None to declare.

\section{Informed Consent}

Informed consent was obtained from this patient.

\section{Author Contributions}

MUK: conception and design, drafting of manuscript; $A B$ : conception and design, drafting of manuscript; BB: conception and design, final approval of manuscript. All Authors have made contributions to the article and have reviewed it before submission.

\section{References}

1. Matrana MR, Margolin DA. Epidemiology and pathophysiology of diverticular disease. Clin Colon Rectal Surg. 2009;22(3):141-146.

2. Ambrosetti P, Robert JH, Witzig JA, Mirescu D, Mathey 
P, Borst F, Rohner A. Acute left colonic diverticulitis in young patients. J Am Coll Surg. 1994;179(2):156-160.

3. Lahat A, Menachem Y, Avidan B, Yanai H, Sakhnini E, Bardan E, Bar-Meir S. Diverticulitis in the young patient is it different? World J Gastroenterol. 2006;12(18):29322935.

4. Painter NS, Burkitt DP. Diverticular disease of the colon, a 20th century problem. Clin Gastroenterol. 1975;4(1):321.

5. Hughes LE. Postmortem survey of diverticular disease of the colon. I. Diverticulosis and diverticulitis. Gut. 1969;10(5):336-344.

6. Painter NS, Burkitt DP. Diverticular disease of the colon: a deficiency disease of Western civilization. Br Med J. 1971;2(5759):450-454.

7. Guzzo J, Hyman N. Diverticulitis in young patients: is resection after a single attack always warranted? Dis Colon Rectum. 2004;47(7):1187-1190; discussion 1190-1181.

8. Schweitzer J, Casillas RA, Collins JC. Acute diverticulitis in the young adult is not "virulent.". Am Surg. 2002;68(12):1044-1047.

9. Pisanu A, Vacca V, Reccia I, Podda M, Uccheddu A. Acute diverticulitis in the young: the same disease in a different patient. Gastroenterol Res Pract. 2013;2013:867961.

10. Schauer PR, Ramos R, Ghiatas AA, Sirinek KR. Virulent diverticular disease in young obese men. Am J Surg. 1992;164(5):443-446; discussion 446-448.

11. Strate LL, Liu YL, Aldoori WH, Syngal S, Giovannucci EL. Obesity increases the risks of diverticulitis and diverticular bleeding. Gastroenterology. 2009;136(1):115-122 e111.

12. Hjern F, Wolk A, Hakansson N. Obesity, physical inactivity, and colonic diverticular disease requiring hospitalization in women: a prospective cohort study. Am J Gastroenterol. 2012;107(2):296-302.

13. Zaidi E, Daly B. CT and clinical features of acute diverticulitis in an urban U.S. population: rising frequency in young, obese adults. AJR Am J Roentgenol. 2006;187(3):689-694.

14. Rezapour M, Ali S, Stollman N. Diverticular Disease: An Update on Pathogenesis and Management. Gut Liver. 2018;12(2):125-132.

15. Parks TG. Natural history of diverticular disease of the colon. Clin Gastroenterol. 1975;4(1):53-69.

16. Wong WD, Wexner SD, Lowry A, Vernava A, 3rd, Burnstein M, Denstman F, Fazio V, et al. Practice parameters for the treatment of sigmoid diverticulitis - supporting documentation. The Standards Task Force. The American Society of Colon and Rectal Surgeons. Dis Colon Rectum. 2000;43(3):290-297.

17. Kaiser AM, Jiang JK, Lake JP, Ault G, Artinyan A, Gonzalez-Ruiz C, Essani R, et al. The management of complicated diverticulitis and the role of computed tomography. Am J Gastroenterol. 2005;100(4):910-917.

18. Rodkey GV, Welch CE. Changing patterns in the surgical treatment of diverticular disease. Ann Surg. 1984;200(4):466-478.

19. Ouriel K, Schwartz SI. Diverticular disease in the young patient. Surg Gynecol Obstet. 1983;156(1):1-5.
20. Freischlag J, Bennion RS, Thompson JE, Jr. Complications of diverticular disease of the colon in young people. Dis Colon Rectum. 1986;29(10):639-643.

21. Minardi AJ, Jr., Johnson LW, Sehon JK, Zibari GB, McDonald JC. Diverticulitis in the young patient. Am Surg. 2001;67(5):458-461.

22. Tan KK, Wong J, Yan Z, Chong CS, Liu JZ, Sim R. Colonic diverticulitis in young Asians: a predominantly mild and right-sided disease. ANZ J Surg. 2014;84(3):181184.

23. Pautrat K, Bretagnol F, Huten N, de Calan L. Acute diverticulitis in very young patients: a frequent surgical management. Dis Colon Rectum. 2007;50(4):472-477.

24. Cunningham MA, Davis JW, Kaups KL. Medical versus surgical management of diverticulitis in patients under age 40. Am J Surg. 1997;174(6):733-735; discussion 735-736.

25. Rafferty J, Shellito P, Hyman NH, Buie WD, Standards Committee of American Society of Colon, Rectal Surgeons. Practice parameters for sigmoid diverticulitis. Dis Colon Rectum. 2006;49(7):939-944.

26. Etzioni DA, Mack TM, Beart RW, Jr., Kaiser AM. Diverticulitis in the United States: 1998-2005: changing patterns of disease and treatment. Ann Surg. 2009;249(2):210217.

27. Hildebrand P, Kropp M, Stellmacher F, Roblick UJ, Bruch HP, Schwandner O. Surgery for right-sided colonic diverticulitis: results of a 10-year-observation period. Langenbecks Arch Surg. 2007;392(2):143-147.

28. Heise CP. Epidemiology and pathogenesis of diverticular disease. J Gastrointest Surg. 2008;12(8):1309-1311.

29. Nguyen GC, Sam J, Anand N. Epidemiological trends and geographic variation in hospital admissions for diverticulitis in the United States. World J Gastroenterol. 2011;17(12):1600-1605.

30. Rosemar A, Angeras U, Rosengren A. Body mass index and diverticular disease: a 28-year follow-up study in men. Dis Colon Rectum. 2008;51(4):450-455.

31. Dobbins C, Defontgalland D, Duthie G, Wattchow DA. The relationship of obesity to the complications of diverticular disease. Colorectal Dis. 2006;8(1):37-40.

32. Shah AM, Malhotra A, Patel B, Spira R, DePasquale JR, Baddoura W. Acute diverticulitis in the young: a 5-year retrospective study of risk factors, clinical presentation and complications. Colorectal Dis. 2011;13(10):11581161.

33. Faria GR, Almeida AB, Moreira H, Pinto-de-Sousa J, Correia-da-Silva P, Pimenta AP. Acute diverticulitis in younger patients: any rationale for a different approach? World J Gastroenterol. 2011;17(2):207-212.

34. Cho KC, Morehouse HT, Alterman DD, Thornhill BA. Sigmoid diverticulitis: diagnostic role of CT - comparison with barium enema studies. Radiology. 1990;176(1):111115.

35. Ambrosetti P, Grossholz M, Becker C, Terrier F, Morel P. Computed tomography in acute left colonic diverticulitis. Br J Surg. 1997;84(4):532-534.

36. Ritz JP, Lehmann KS, Stroux A, Buhr HJ, Holmer C. Sigmoid diverticulitis in young patients - a more aggres- 
sive disease than in older patients? J Gastrointest Surg. 2011;15(4):667-674.

37. Jensen TK, Eiholm S, Achiam MP. [Caecal diverticulitis in a young woman with suspected acute appendicitis]. Ugeskr Laeger. 2013;175(50A):V06130356.

38. Age limits and adolescents. Paediatr Child Health. 2003;8(9):577-578.

39. Valenzuela-Salazar C, Orozco-Tapia LM, de la Concha Blankenagel E, Gallardo-Ramirez MA, Blas-Franco M, Cardenas-Lailson LE. [Sigmoid diverticulitis in adolescent. Case report]. Cir Cir. 2013;81(5):445-449.

40. Sigaloff KC, van den Berg JG, Benninga MA. Cecal di- verticulitis in an adolescent. J Pediatr Gastroenterol Nutr. 2005;40(5):603-605.

41. Halata MS, Newman LJ, Easton LB, Dove D, Stone RK. Diverticulitis in an adolescent. Clin Pediatr (Phila). 1983;22(10):716-718.

42. Afzal NA, Thomson M. Diverticular disease in adolescence. Best Pract Res Clin Gastroenterol. 2002;16(4):621634.

43. Lopez-Borao J, Kreisler E, Millan M, Trenti L, Jaurrieta E, Rodriguez-Moranta F, Miguel B, et al. Impact of age on recurrence and severity of left colonic diverticulitis. Colorectal Dis. 2012;14(7):e407-412. 